\title{
Understanding the Implementation \& Integration of Remote \& Tele-Health Services ... an Overview of Normalization Process Theory
}

\author{
Matt-Mouley Bouamrane ${ }^{1}$, Janice Osbourne ${ }^{2}$, Frances S. Mair ${ }^{1}$ \\ ${ }^{1}$ College of Medical, Veterinary and Life Sciences, \\ Academic Unit of General Practice and Primary Care \\ Institute for Health and Well-Being, \\ University of Glasgow, Scotland \\ \{Frances.Mair, Matt-Mouley.Bouamrane\}@glasgow.ac.uk \\ ${ }^{2}$ Cranfield University, School of Management, U.K. \\ Janice.Osbourne@cranfield.ac.uk
}

\begin{abstract}
Policymakers worldwide are increasingly supporting the development of nation-wide tele-healthcare, assisted living and healthy-living technology programs. To support transformation processes within healthcare systems, the computing and Interaction Design community must continually strive to identify, describe, understand and reassess the factors causing users to adopt - and also often reject - technology. We review the Normalization Process Theory, a theoretical model of processes of intervention within the health services. The theory has been iteratively developed over the last decade by health services practitioners and researchers, with direct experience of analysing modalities and impact of changes resulting from complex technological interventions within the health services. The theory is of direct relevance to all designers involved in developing or evaluating the deployment of electronic tele-health-care, assisted living and healthy-living technology.
\end{abstract}

\section{Introduction}

Many telemedicine and tele-healthcare short term studies have failed to be integrated into routine practice. Several factors have been identified in the literature as accounting for this. Amongst them have been, insufficient evidence of efficacy, involvement of a wide range of stakeholders with different expectations and needs, and the difficulty of integrating systems.

The Normalization Process Theory (NPT), is a theoretical model of processes of intervention within the health services which provides a conceptual framework to identify, describe, explain and anticipate the factors which explain why certain interventions succeed or fail, even when benefiting from considerable support among patients, health professionals, policymakers and other stakeholders. We begin in section 2 by describing issues with the continued sustainability of existing models of care - and the potential opportunities for new technologies in addressing these challenges. This is followed in section 3 by a description of the Normalization Process Model (NPM) and the theory which subsequently developed from this model: the Normalization Process Theory. We discuss other theories of technological innovation in section 4 . We review the application of NPT to 3 selected case-studies in section 5: tele-dermatology, tele-monitoring of patient with chronic lung disease and tele-psychiatry. We conclude with a discussion and directions for future development of the theory in section 6 .

\section{Long term Challenges}

\subsection{Models of Care}

Existing models of care are unsustainable in the long term - neither economically or whether in terms of the availability of a competent workforce to cater for an increasing elderly population with complex needs. Part of the agenda in driving changes in the delivery of care is now to try to promote coherent nationwide policies focused on prevention, healthy living and community-based care. New models of care delivery would seek to reduce the reliance on acute services while supporting delivery of care and healthy living within the community s well as tele-health-care programmes [1, 2, 17]. Yet, large scale deployment remains a challenge due to the complexity of needs, issues with interoperability of systems and the fragmentation of the ehealth industry. In addition, there are a lack of widely 
adopted standards, a lack of underlying clinical evidencebased of successful outcomes and entrenched resistance to innovation from certain services users - and indeed services providers.

\subsection{Electronic and Tele-Health-Care}

Telehealth has the potential to facilitate access to routine appointments and specialist services, at a distance, in a context of increasing demands for services, potential inefficiencies in services provision, and unequal access to services across geographical locations. Provisions of services can be synchronous (e.g. using videoconferencing systems) or asynchronous, (e.g. e-mails, electronic repositories). Some fields of healthcare provision seem particularly well suited to telehealth, namely: (i) those which require a high level of specialist expertise, which can not realistically be expected to be equally geographically distributed across the country, or (ii) those where triage, referral, diagnoses or management can be decided on the basis of textual, visual or other forms of digital information, and where the physical presence of the patient is not deemed essential, or indeed necessary. NHS direct and NHS $24^{1}$ are examples of telehealth services routinely used in the U.K. In other cases, the failure of e-health systems to become routinely used within the health services is not necessarily a consequence of design or technological flaws with the systems themselves (see Taylor's insightful description of the issues surrounding health informatics in [19]). Many factors could at play: disruption to services, a mismatch between functionalities of the system and work practices, or resistance or even rejection by end-users for reasons including: concerns regarding patient/practitioner relationship, the need to redefine structures, roles and hierarchies, perceived threat to status within the organisation, fear of a lesser role, becoming redundant, etc. (see the case studies analysed in section 5).

\section{Normalization Process Model \& Theory}

\subsection{Normalization Process Model - NPM}

NPM is a prospective process evaluation model which draws on sociological models of group processes in structured organisation contexts, leading to operationalisation $[10,12,15]$. The model contends that interventions are implemented in processes in which operationalisation and interactions are governed by 4 workability (2) and integration (2) constructs which are detailed in Table 1. These constructs have cooperative attributes (type $a$.: negotiations and

\footnotetext{
${ }^{1}$ Online and telephone services used by member of the public to describe their symptoms before being instructed whether or not to present themselves at general practice or emergency.
}

agreements between agents) and executive attributes (type $b$ : enacting the intervention). The model offers a set of general descriptions of factors which may affect the normalization of processes and outcomes of complex intervention.

Based on the 4 dimensions defined in Table 1, the model makes a number of formal propositions extracted from observed regularities in experimental data collated during interventions over several years $(2000$ - 2007) [10, 15]. The model proposes that a complex intervention is disposed to normalization if :

- (i) "it confers an interactional advantage in flexibility accomplishing congruence (i.e. cooperative work) and disposal (i.e. outcomes) of work." [Interactional Workability] - (ii) "it equals or improves accountability (i.e. individual working knowledge) and confidence (i.e. understanding of others and of broader intervention) within networks".

\section{[Relational Integration]}

- (iii) "it is calibrated to an agreed skill-set at a recognizable location in the division of labour". [Skill-set workability]

- (iv) "it confers an advantage on an organisation in flexibility executing and realising work”.

\section{[Contextual Integration]}

The previous propositions effectively state that, in order to be successfully integrated within the work practices of an organisation, a complex intervention needs to demonstrate that: it improves flexibility, cooperation or the outcomes of work (i), it improves the working knowledge of individuals and that people understand how their work fit with that of others (ii), that responsibilities are well-defined and that people have the necessary skills to perform their work (iii) and finally, that the intervention is supported and provides organisation-wide benefits (iv).

Within Relational Integration, it is important to highlight the distinction between the knowledge underpinning an intervention (e.g. knowledge of a specific chronic disease) and its application in clinical setting (e.g. management of patients with the disease, perhaps with a tele-healthcare system), or its perception by the recipients (e.g. how the patients treated feel about the intervention). One crucial aspect of Contextual Integration is that by nature, an new intervention will need to compete with already existing, integrated, and perhaps even entrenched, work practices and behaviours.

\subsection{Normalization Process Theory - NPT}

Normalization Process Theory builds on and extends the previous model of derived empirical generalisations from experimental data in order to identify and understand the general phenomena of implementation processes. It seeks to provide the necessary concepts for (i) description of phe- 
Table 1. The 4 Dimensions of the Normalization Process Model, adapted from May et al. $(2006,2007)$

\begin{tabular}{|c|c|c|c|}
\hline \multicolumn{2}{|c|}{ Workability } & \multicolumn{2}{|c|}{ Integration } \\
\hline \multicolumn{2}{|c|}{ 1. - Interactional Workability } & \multicolumn{2}{|c|}{ 2. - Relational Integration } \\
\hline \multicolumn{2}{|c|}{ - social context in which work is enacted by agents } & \multicolumn{2}{|c|}{$\begin{array}{l}\text { - How work is understood individually and within networks } \\
\text { - Confidence in the roles of others. }\end{array}$} \\
\hline $\begin{array}{l}\text { 1a. Congruence } \\
\text { (Interaction) }\end{array}$ & $\begin{array}{l}\text { 1b. Disposal } \\
\text { (Effects of interaction) }\end{array}$ & $\begin{array}{l}\text { 2.a Accountability } \\
\text { (Knowledge) }\end{array}$ & $\begin{array}{l}\text { 2.b Confidence } \\
\text { (Beliefs) }\end{array}$ \\
\hline $\begin{array}{l}\text { - legitimate actions } \\
\text { - form of work } \\
\text { - role of participants } \\
\text { - how work is completed } \\
\text { in available space and time } \\
\text { - formal and informal rules } \\
\text { - verbal and non-verbal } \\
\text { conduct of an interaction }\end{array}$ & $\begin{array}{l}\text { - goals of interaction } \\
\text { - minimise disagreement } \\
\text { about outcomes } \\
\text { - when and where goals } \\
\text { and outcomes occur } \\
\text { - shared beliefs of meaning } \\
\text { \& consequences of work } \\
\text { - human computer } \\
\text { interaction }\end{array}$ & $\begin{array}{l}\text { - knowledge and practices of } \\
\text { agents enacting work } \\
\text { - knowledge required to enact } \\
\text { work, contribution expected } \\
\text { - ownership of knowledge } \\
\text { - disagreements over ownership } \\
\text { - formal \& informal rules of } \\
\text { distribution of knowledge }\end{array}$ & $\begin{array}{l}\text { - agreement over } \\
\text { authoritative knowledge } \\
\text { and practice } \\
\text { - criteria and assessment } \\
\text { of credibility } \\
\text { - beliefs about practical } \\
\text { utility and reliability }\end{array}$ \\
\hline \multicolumn{2}{|c|}{ 3. - Skill-set Workability } & \multicolumn{2}{|c|}{ 4. - Contextual Integration } \\
\hline \multicolumn{2}{|c|}{$\begin{array}{l}\text { - Place of work within division of labour and the necessary } \\
\text { skills to perform it } \\
\text { - Specification of roles; issues around overlapping } \\
\text { responsibilities }\end{array}$} & \multicolumn{2}{|c|}{$\begin{array}{l}\text { - Organizational-wide level sponsorship and control of work } \\
\text { - Resources allocation }\end{array}$} \\
\hline $\begin{array}{l}\text { 3a. Allocation } \\
\text { (Tasks) }\end{array}$ & $\begin{array}{l}\text { 3b. Performance } \\
\text { (Effectiveness) }\end{array}$ & $\begin{array}{l}\text { 4.a Execution } \\
\text { (Practicalities) }\end{array}$ & $\begin{array}{l}\text { 4.b Realisation } \\
\text { (Responsibility) }\end{array}$ \\
\hline $\begin{array}{l}\text { - which tasks are performed } \\
\text { - who perform the tasks } \\
\text { - who allocate the tasks } \\
\text { - distribution of resources } \\
\text { and rewards according } \\
\text { to status and authority } \\
\text { - identification and } \\
\text { assessment of skills } \\
\text { - definition and ownership } \\
\text { of skill-sets }\end{array}$ & $\begin{array}{l}\text { - staff training } \\
\text { - policies defining } \\
\text { boundaries of competence } \\
\text { - autonomy of workers } \\
\text { - delivery of services }\end{array}$ & $\begin{array}{l}\text { - decisions regarding } \\
\text { distribution of resources } \\
\text { - managerial decision- } \\
\text { making } \\
\text { - costs and risks within } \\
\text { organisation } \\
\text { - formal and informal } \\
\text { evaluation mechanisms }\end{array}$ & $\begin{array}{l}\text { - negotiations necessary } \\
\text { to modify existing } \\
\text { systems \& practices } \\
\text { - making new practices } \\
\text { possible } \\
\text { - minimise disruption } \\
\text { and risks of change } \\
\text { - how are resources } \\
\text { obtained and used }\end{array}$ \\
\hline
\end{tabular}


Table 2. NPT - Generative Mechanisms

\begin{tabular}{|l|}
\hline 5. - Coherence \\
\hline - ways by which agents make sense of a set of \\
practices. \\
- coherence requires that agents collectively invest \\
meaning. \\
\hline 6. - Cognitive Participation \\
\hline - means by which participation in a set of practices \\
is defined and organised. \\
- embedding is shaped by factors which promote or \\
inhibit participation. \\
\hline 7. - Collective Action / Operationalisation \\
\hline - means by which agents define and organise a set \\
of practices. \\
- embedding is shaped by factors which promote \\
or inhibit the enacting of a set of practices. \\
\hline 8. - Reflexive Monitoring \\
\hline - forms of appraisal that agents apply to a set of \\
practices. \\
- embedding requires that agents collectively invest \\
in the understanding of a set of practices. \\
\hline
\end{tabular}

nomena, (ii) explanation of causality and relation mechanisms between phenomena and (iii) provide new knowledge about the phenomena. It is concerned with 3 main issues:

- Implementation: the social organisation of bringing a practice into action.

- Embedding: processes through which a practice becomes routinely incorporated in everyday work, individuals and group.

- Integration: processes by which practices are reproduced and sustained.

The NPT theory make the following propositions:

- (i) "practices become normalised as the result of individual and collective action to enact them..."

- (ii) "enacting is promoted or inhibited through the operation of generative mechanisms...” (see Table 2)

- (iii) "the (re-)production of practices require continuous investments by agents...”

We refer the interested reader to a more detailed description of the theory in $[11,14]$ and an online tool-kit is also now available ${ }^{2}$. We now discuss in the next section other theories of technological innovation before discussing the applicability of NPT to a number of selected e-health interventions described in section 5 .

\section{Theories of Innovation}

One of the main issues in the HCI and information systems literature - and which has been debated at length -

\footnotetext{
${ }^{2}$ http://www.normalizationprocess.org/npt-toolkit.aspx
}

is identifying factors which cause people to accept, adopt and implement technology developed by others. One approach which has proven helpful is through the use of theories and models, developed to predict and explain technology behaviour. These have included popular models such as the Technology Acceptance Model, (TAM) [6], the Theory of Planned Behaviour, (TPB) [3] and the Diffusion of Innovation Theory [18], which have been widely accepted and have had their validity proven in areas such as information technology, business, health, and agriculture to name a few. Additionally, where the models have not explained all the factors, they have been extended and revised for better understanding. Within the health sector, the use of theory to understand users and organisational behaviour is increasing as more ICT and digital devices are being developed and used in the industry to improve delivery of care. The theories normally applied within the health domain have focused on studying the explanatory and predictive validity of the individual theories. These include the TPB, Theory of Reasoned Action, (TRA), and the Social Cognitive Theory, (SCT). In SCT, behaviour is a result of the interaction between personal, environmental and behavioural factors [5].

The Theory of Reasoned Action is a social psychology theory developed to measure the intention of an individual to engage in a given behaviour in addition to accounting for behaviours that are under volitional control [4, 8]. TRA developed from work on psychosocial processes and is based on the following concepts: Subjective Norm, which is the perceived opinion of other people in relation to the behaviour in question, Attitude represents "an individual's positive or negative feelings (evaluative affect) about performing the target behaviour, and the Intention to perform a behaviour is determined by an individuals attitude and subjective norms.

The Theory of Planned behaviour is an extension of the TRA and includes constructs of Control Belief and Perceived Behavioural Control (perception of ease or difficulty in performing the behaviour of interest). The model was proposed to deal with the limitations of the previous model when dealing with behaviour over which individuals have incomplete volitional control. Intention is determined by attitude, subjective norm and perceived behavioural control. The Technology Acceptance Model (TAM) was adapted from TRA and specifically tailored for modelling user acceptance of information systems [20]. The attitudinal constructs of TRA were replaced with two beliefs: perceived usefulness and perceived ease of use. TAM was extended with the addition of two constructs: cognitive instrumental processes and social influence processes.

Diffusion Theory examines the process by which an innovation is accepted or rejected by particular individuals or organisations over a period of time. Rogers defined diffusion as "the process by which an innovation is communi- 
Table 3. Facilitators of tele-dermatology

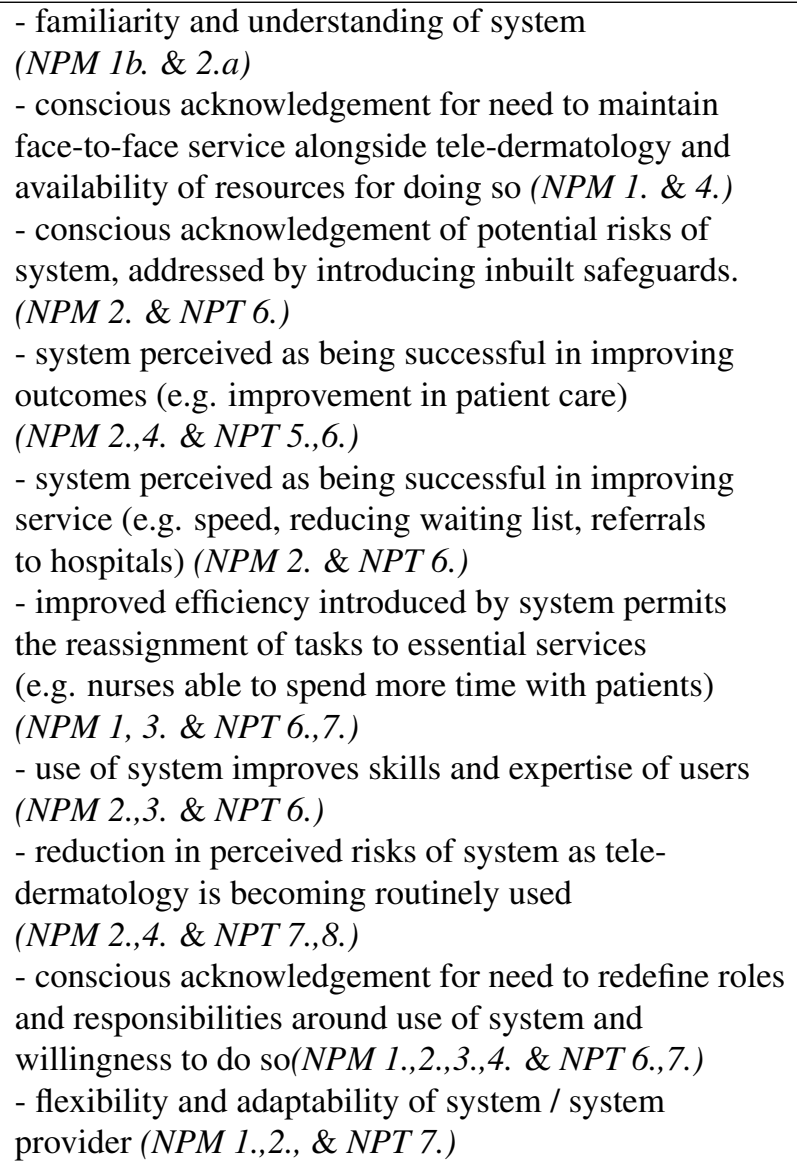

cated through certain channels over time among the members of a social system"[18]. It is centred around four areas: the innovation, the social systems, the characteristics of the adopters and the communication channels. The theory constructs include: trialability (the degree to which an innovation may be experimented with on a limited basis), complexity (the degree to which an innovation is perceived as difficult to understand and use), compatibility (the degree to which an innovation is perceived as being consistent with existing values, past experiences, and needs of potential adopters), relative advantage (the degree to which an innovation is perceived as better than the idea it supersedes), observability (the degree to which the results of an innovation are visible to others), communication channel (the means by which interaction takes place between individuals in an organisation). Additionally most of the theories can be organized into four categories, belief attitude theories, competence-based theories, control-based theories and decision-making theories with the primary emphasis being to understand the psychology behind why people making decision either individually or within a social context [16].

\section{Case Studies}

\section{$5.1 \quad$ Tele-Dermatology}

Tele-dermatology has been identified as a specialty well suited to e-health implementation, as it has demonstrated both high medical concordance with face-to-face consultations as well as positive feed-back from patients.

Using longitudinal qualitative study analysis, Finch, Mair \& May analysed 12 tele-dermatology studies over 8 years (1997-2005), which included 68 interviews with: consultant dermatologists (19), tele-dermatology nurses (11), doctors (3), patients advocates (4), administrators (8), technologists (6) and researchers (17) (these figures refer to the number of interviews as there were multiple interviews with a single practitioner in certain cases) [7]. Of the 12 studies included in the survey, 6 led to a normalization of teledermatology - a service was implemented and integrated within work practices - and 6 ended in failure of normalization - the tele-dermatology services were eventually discontinued.

Table 3 and 4 summarise identified factors promoting or inhibiting the normalization of tele-dermatology services. All the services still in operation at the time of the survey were asynchronous repository, (store-and-forward) systems for review, triage and advice.

Interestingly, the original goal of using tele-dermatology for addressing consultants shortage and reducing waiting lists failed overall, but this did not prevent certain teledermatology services being sustained, either as a major new service or as a complement to existing service provision. Flexibility and cross-sector professional support were essential to the successful deployment of the technology.

\subsection{Tele-Monitoring of Chronic Diseases}

Mair, Hiscock \& Beaton conducted a qualitative study embedded in a RCT of a remote monitoring system for people with acute chronic obstructive pulmonary disease (COPD) [9]. The system consisted of a videophone link and devices permitting monitoring of blood pressure, pulse, temperature and pulse oximetry. 12 specialist respiratory nurses and 104 patients took part in the RCT trial. 9 patients and 11 nurses took part in the qualitative study which involved observation of participants in the home care service and semi-structured interviews.

The conclusions of this study was that the technology had overall very little chance of becoming normalised, as is evidenced by the considerable number of barriers identified in table 5. There was a particularly strong dichotomy between the perceptions of the specialist nurses and the patients: with the patient being generally satisfied with the 
service and the nurses strongly dissatisfied. The authors acknowledge a number of specificities to the study and the results can not necessarily be generalised to other long-term monitoring systems.

There were non-negligible technical issues with the system. The nurses also had to install the system themselves and this presented a significant problem. It might not have been such a problem if the installation had been straightforward but this did not necessarily seem to be the case in most cases. The nurses probably lacked confidence in trouble-shooting the system (issues of interactional workability and relational integration). It is possible that they also saw this as a downgrade of their skills (issues of skillset workability).

There seemed to have been a lack of available resources for a technician to perform this task (issues of contextual integration). Other barriers included the fact that the patients had acute illnesses and therefore, there were legitimate safety concerns about the system and potential medical liabilities for the nurses themselves.

A considerable issue overall was that the specialist nurses felt their roles and identities undermined and perhaps even their livelihood threatened by the system (issues of $\mathrm{Co}$ herence and Cognitive Participation). Finally, the nurses seemed to have been running both an innovative and efficient service before this intervention and overall, the telemonitoring system seemed to have mostly contributed to a disruption of the service, at least from the nurses' point of view. Although, the results of the study may not be generic, they are useful none-the-less to illustrate how a combination of technical problems and lack of careful attention to the impact of role reconfiguration entailed by the introduction of a new system may well lead to normalisation failure.

\subsection{Tele-Psychiatry}

May et al. conducted a qualitative study of a telepsychiatry system over a 6 months periods and included interviews with 15 professionals (healthcare, technical and managers) and 22 interviews with patients [13]. The ehealth service consisted of using a videophone unit which linked a general practice to a community mental health team (CMHT) based in a psychiatric outpatients' clinic 10 miles away. The purpose of the trial was to evaluate the feasibility of using the system for the routine referral of patients with anxiety and depression from the general practice to the mental health team, with an initial consultation between a patient and a mental health professional. Patients with substance misuse problems or affected by delusions or psychotic illnesses were not eligible. Initially, members of the CMHT were enthusiastic about the potential benefit of the system in saving the patient a journey to the CMHT and in cutting waiting lists and reducing the time for an initial as-

\section{Table 4. Barriers to tele-dermatology}

\begin{tabular}{|c|}
\hline 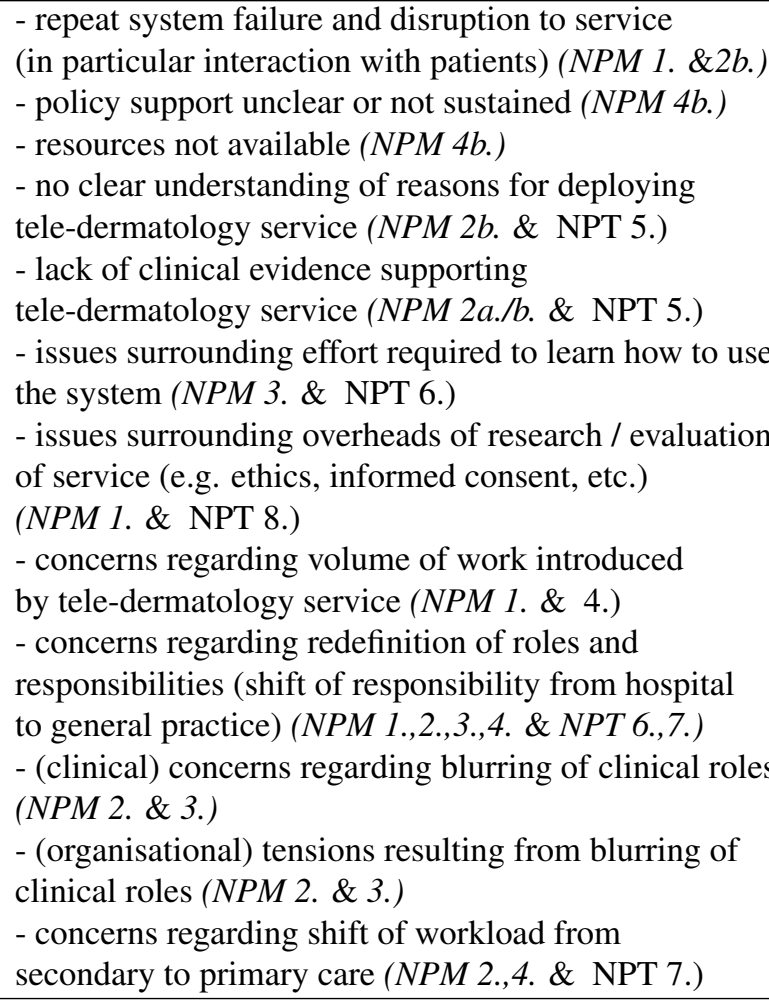 \\
\hline
\end{tabular}

sessment from 6 weeks to a few days. However, the study demonstrated that this initial enthusiasm quickly faded.

Although some technical issues and limitations may explain to some extent some of the concerns raised, the results of the survey seem to suggest that the technology itself seriously interfered and disrupted the nature of the therapeutic encounter. This suggest considerable issues of interactional workability as being major obstacles to the normalisation of tele-psychiatry services, due to the specific nature of the clinical encounter in which the physical co-presence of the patient and the health professional seem to be intrinsically therapeutic. Interestingly, the members of the mental health team seemed to have initially underestimated the importance of this aspect, and it is only when confronted with the use of the tele-healthcare system that they became fully aware of it.

\section{Discussion}

The previous case studies have shown that normalisation of e-health services were successful when the following facilitating factors were present in the intervention [7]:

- Benefits of Intervention: the perception that the benefits introduced by the new technology and services outweighed the necessary efforts and commitment required for the reor- 
Table 5. Facilitators \& Barriers to telemonitoring service of patients with chronic lung condition, Mair et al. 2008

\begin{tabular}{|l|}
\hline \multicolumn{1}{|c|}{ Facilitators } \\
\hline - familiarity and understanding of system (nurses) \\
$(N P M 1 b . \& 2 . a)$ \\
- patient satisfaction with system (more autonomy) \\
- patient empowerment with increased responsibility \\
in understanding and managing their own condition \\
$(N P M$ 1., 3.) \\
\hline \hline
\end{tabular}

Barriers
(performed by the nurses who felt this to be entirely inadequate both in terms of time and skills required as well as a misuse of their own time and skills and thought it should have been the role of a technician) (NPM 1.,4. \& NPT 5.)

- poor quality of service (picture and sound quality) (NPM 1.)

- poor quality of communication with patient

(NPM 1.)

- unreliability of physiological monitoring (NPM 1.)

- issues of general trust of system and equipment

(NPM 1.)

- concerns that the use of the system made work more difficult and less effective (NPM 1. \& NPT 5.)

- concerns that the clinical effectiveness of

consultations was reduced as a result of using

the system (NPM 1.\& NPT 5.)

- issues of mismatch of perceptions in usability and safety of system between nurses (dissatisfied)

and patients (generally satisfied) (NPM 1. \& NPT 5.)

- concerns about negative impact on patient-nurse

relationship (mostly felt by the nurses not patients)

- (nurse) concerns regarding alteration of work as face-to-face interaction and relationship with patient is considered to be at the core of their duty threat to holistic nature of their work

(NPM 1. \& NPT 5.)

- (nurse) concerns regarding alteration of own role (NPM 3.\& NPT 5.)

- (nurse) concerns regarding shift of responsibilities to patient, in particular regarding safety concerns (NPM 3.\& NPT 5.)

- (nurse) medico-legal concerns and fears of liability (NPM 3.\& NPT 5.)

- (nurse) concerns regarding redundancy of skills and role if tele-monitoring (NPM 3.\& NPT 5.)

- (nurse) concerns regarding overall legitimacy of system (NPM 2.,3.\& NPT 5.)

\section{Table 6. Barriers to tele-psychiatry services}

- (GP) regarding how patients would respond to
service, that tele-psychiatry would be impersonal
and lack empathy (NPM 1.,2.)
- CMHT concerns that technology shaped and
constrained the therapeutic encounter
(e.g. having to maintain eye-contact at all time,
non being able to use usual non-verbal cues of face-to-
face consultations) and that (e.g. soothing) effect of
physical presence in face-to-face consultation was
irreversibly compromised by remote system
- concerns that using the system made consultation
more tense and that the device became the focus of
the consultation rather than the patient /
MH professional interaction (NPM 1.)
- concerns that system was not adequate for all
type of patients (e.g. too talkative) (NPM 1.)
- concerns that MH professionals could not intervene
in emergency (e.g. distress, self-harm)
- concerns that reducing waiting list had an unexpected
negative impact on therapeutic outcomes (i.e. patients
consulted GP at time of crisis and 6 weeks delay in
consultation gave him time to "settle down")

ganisation of the former services.

- Trust: a willingness, at least initially, to rely on pragmatic demonstration of usefulness rather than clinical evidence.

- System Flexibility: allowing for flexibility in the functionalities and use of systems rather than expecting services and roles to reconfigure around new technology.

- Autonomy \& Risk Management : acknowledging risks introduced by the use of the new technology and associated reorganisation of services and redefinition of roles. Making conscious provisions for these risks in the forms of a combination of in-built safe-guards within the systems and professional autonomy and judgement.

- Organisational Flexibility: allowing for flexible redefinition of roles and responsibilities around new technology. - Local Context: allowing for specificity and tailoring of services according to local policies and context.

In contrast, the tele-monitoring study described in [9] is useful in illustrating how a combination of a system beset with technical problems, together with lack of careful consideration to role reconfiguration in the reorganisation of services is likely to lead to a technology normalisation failure.

The study of the tele-psychiatry service described in [13] suggests very serious interactional workability issues in this specific field of healthcare, as the technology proved to seriously interfere and disrupt the therapeutic encounter. Interestingly, the mental health professionals were initially en- 
thusiastic about the use of the technology. The trial of the tele-psychiatry service was useful in helping the CMHT become aware of what was important and therapeutically effective in their interaction with patients and how the use of technology compromised these aspects [13]. This is a very important finding in itself.

From a health organisation's perspective, the case studies would suggest keeping an open-mind regarding the potential benefits of new technology. Helping professionals making sense of what they do could be an important by-product of technology trials, even if these do not always translate to successful normalisation.

An intervention could be deemed useful, even if it did not necessarily achieve its initial goals (e.g. reducing waiting lists in tele-dermatology service) but nevertheless produced some cost-effective improvement in delivery or efficiency of services. The studies suggest that successful services are possible through functional relationships, characterised by trust and adaptability, between the various agents involved. The desired outcome of an intervention should therefore be a reorganisation of services around new functional relationships. Normalisation is thus, achieved when the result of an intervention leads to a reorganisation of services where technology is embedded within redefined and functional relationships ( see Figure 1).

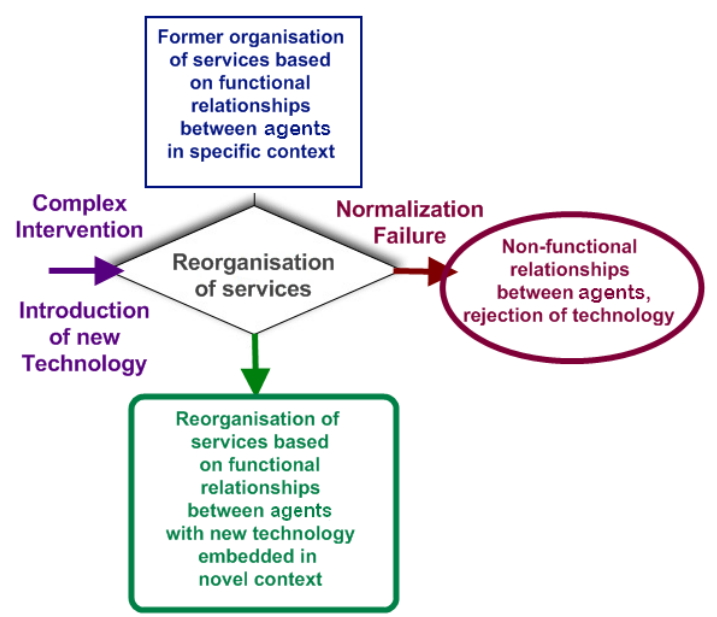

Figure 1. Normalisation of services

\section{References}

[1] Seizing the Opportunity: Telecare Strategy 2008-10, Joint Improvement Team / Scottish Government publication, 33 p. Technical report, 2008.

[2] The Carers Strategy for Scotland 2010 - 2015, Scottish Government publication, $140 \mathrm{p}$. Technical report, 2008.

[3] I. Ajzen. From Intentions to Actions: A Theory of Planned Behavior. Action Control: From Cognition to Behavior, in J.
Kuhl \& J. Beckmann, eds., Springer, New York, pages 11-39, 1985.

[4] I. Ajzen and M. Fishbein. Understanding attitudes and predicting social behavior. Englewood Cliffs, NJ: PrenticeHall., 1980.

[5] A. Bandura. Human agency in social cognitive theory. American Psychologist, 44:1175-1184, 1989.

[6] F. D. Davis, R. P. Bagozzi, and P. R. Warshaw. User acceptance of computer technology: a comparison of two theoretical models. Management Science, 35(8):982-1003, 1989.

[7] T. Finch, F. Mair, and C. May. Teledermatology in the United Kingdom: lessons in service innovation. British Journal of Dermatology, 156:521-527, 2007.

[8] M. Fishbein and I. Ajzen. Belief, attitude, intention, and behavior: An introduction to theory and research. Reading, MA: Addison-Wesley., 1975.

[9] F. Mair, J. Hiscock, and S. Beaton. Understanding factors that inhibit or promote the utilisation of telecare in chronic lung disease. Chronic Illness, 4(2):110-117, 2008.

[10] C. May. A rational model for assessing and evaluating complex interventions in health care. BMC,Health Services Research, 6:86, 2006.

[11] C. May and T. Finch. Implementing, Embedding, and Integrating Practices: An Outline of Normalization Process Theory. Sociology, 43:535554, 2009.

[12] C. May, T. Finch, F. Mair, L. Ballini, C. Dowrick, M. Eccles, L. Gask, A. MacFarlane, E. Murray, T. Rapley, A. Rogers, S. Treweek, P. Wallace, G. Anderson, J. Burns, and B. Heaven. Understanding the implementation of complex interventions in health care: the Normalization Process Model. BMC Health Services Research, 7(148):7p., 2007.

[13] C. May, L. Gask, T. Atkinson, N. Ellis, F. Mair, and A. Esmail. Resisting and promoting new technologies in clinical practice: the case of telepsychiatry. Social Science and Medicine, 52:1889-1901, 2001.

[14] C. May, F. Mair, T. Finch, A. MacFarlane, C. Dowrick, S. Treweek, T. Rapley, L. Ballini, B. N. Ong, A. Rogers, E. Murray, G. Elwyn, F. Lgar, J. Gunn, and V. M. Montori. Development of a theory of implementation and integration: Normalization Process Theory. Implementation Science, 4(29):9p., 2009.

[15] C. R. May, F. S. Mair, C. F. Dowrick, and T. L. Finch. Process evaluation for complex interventions in primary care: understanding trials using the normalization process model. BMC Family Practice, 8(42):9 p., July 2007.

[16] C. R. Nigg, J. P. Allegrante, and M. Ory. Theory-comparison and multiple-behavior research: common themes advancing health behavior research. Health Education Research, $O x$ ford Journals, 17(5):670-679.

[17] L. D. of Denham KBE. High quality care for all: NHS Next Stage Review final report, Command Paper, Crown publishing, 92 p. Technical report, 2009.

[18] E. M. Rogers. Diffusion of innovations (4th ed.). New York: Free Press, 1995.

[19] P. Taylor. From Patient Data to Medical Knowledge: The Principles and Practice of Health Informatics. BMJ, Blackwell Publishing, 2006.

[20] V. Venkatesh and F. D. Davis. A Theoretical Extension of the Technology Acceptance Model: Four Longitudinal Field Studies. Management Science, 46(2):186-204, 2000. 